\title{
Lived Experiences of Women Facing Domestic Violence in India
}

\author{
Shreya Bhandari \\ Wright State University \\ Jennifer $\mathbf{C}$. Hughes \\ Wright State University
}

\begin{abstract}
This article describes the lived experiences of domestic violence victims among a convenience sample of 21 low-income Indian women. The experiences of abuse are drawn from in-depth, face-to-face interviews conducted in Mumbai, India. The qualitative analysis describes four major categories of their lived experiences: (a) types of abuse, (b) family involvement in abuse, (c) treatment of children, and (d) abandonment. Domestic violence in Indian culture includes violence from the husband as well as the in-laws. Women are expected to endure violence for fear of bringing shame to their families. Social and financial support for abused woman is lacking.
\end{abstract}

Keywords: domestic violence, India, lived experiences

\section{Introduction}

The World Health Organization (2016) estimated that $35 \%$ of women worldwide have experienced some form of violence, with the vast majority of this violence against women being intimate partner violence. The World Health Organization reports that one third of these women $(30 \%$ of women worldwide) have experienced domestic violence (DV). The prevalence of reported DV among Indian states varies from 6\% in Himachal Pradesh, to 59\% in Bihar (Charlette, Nongkynrih, \& Gupta, 2012; Garcia-Moreno, Jansen, Ellsberg, Heise, \& Watts, 2005). DV has been defined as "any form of coercion, power, and control—physical, sexual, verbal, mental, or economic-perpetuated on a woman by her spouse, ex-spouse or extended kin, arising from the social relations that are created within the context of marriage" (Abraham, 1998, p. 221). According to the Protection of Women From Domestic Violence Act (2005), the definition of DV also includes harassment by way of unlawful dowry demands on the woman or her relatives (Vindhya, 2000). Several studies have identified factors associated with a greater probability of DV among women in India, including an inability to perform household duties and responsibilities, financial abuse and strain, hierarchical gender relationships, lower household income, illiteracy, exposure to violence during childhood, belonging to a lower caste, an inability to have a male child, a younger age at the time of marriage, employment status, insufficient dowry, and partner's use of alcohol (Dutta, Rishi, Roy, \& Umashankar, 2016; Kamat, Ferreira, Motghare, Kamat, \& Pinto, 2010; Mahapatro, Gupta, \& Gupta, 2012; Raj et al., 2010; Sinha et al., 2012; Visaria, 1999).

This Research is supported and funded through a College of Liberal Arts Faculty Research Activity Grant $(\$ 5,000)$ and Wright State University Professional Development funds (\$900). 


\section{Culturally Specific Ways in Which Women Experience DV in India}

Culture plays an important role in DV cases in India. Gender roles, in particular, are patriarchal and rigid (Panchanadeswaran \& Koverola, 2005). Women tend to be in passive roles whereas men tend to dominate and control relationships. Marriage is considered a sacrosanct union between two families rather than between individuals. In this context, women's primary roles are her marriage and motherhood (Sharma, Pandit, Pathak, \& Sharma, 2013). According to Kalokhe et al. (2015), culture plays a role in abusive behaviors. For instance, Indian culture emphasizes the value of childbirth after marriage and especially favors the birth of male children. Therefore, infertility or failure to give birth to a male child may increase women's risk of experiencing DV (Kalokhe et al., 2015). Kalokhe and colleagues also report that cultural beliefs contribute to the perpetration of abuse by in-laws against a daughter-in-law. The husband's family has the right to evict the woman from the marital home for insufficient dowry and to then force her to return to her natal family. In some cases, women experience physical abuse by their in-laws for the same reason (Kalokhe et al., 2015). Thus, strict patriarchal norms, stringent gender roles, societal acceptance of wife beating, gender inequities, and a strong preference for male offspring, among other factors, are associated with rampant DV in India (Dreze \& Khera, 2000; Koenig, Stephenson, Ahmed, Jejeebhoy, \& Campbell, 2006; Martin et al., 2002).

\section{Why This Research Is Important}

The frequency of DV reports in India is growing and has elevated concern for the plight of Indian women to the global level. Despite the alarming levels of DV (Dutta et al., 2016), however, this epidemic has not received sufficient attention by social work researchers (Sujatha, 2014). Most research so far has featured large quantitative studies that focus on the prevalence of DV in India (Begum, Donta, Nair, \& Prakasam, 2015; Sabri, Renner, Stockman, Mittal, \& Decker, 2014). Such studies fail to give a voice to the unique lived experiences of the women at the heart of the research. Due to the high prevalence of DV in India and the limited understanding of this understudied population, the present study focuses on the lived experiences of women in India who have reported DV using the conceptual framework of the Duluth Power and Control Wheel (see Figure 1). DV is a combination of different tactics that the abuser uses to maintain power and control (words at the center of the wheel) over the victim. The diagram portrays the tactics an abusive partner uses to keep the victim in the relationship. Whereas the inside of the wheel consists of subtle, continual behaviors, like using threats and intimidation, the outer circle ring clearly states the various blatant forms of violence. The abusive acts in the outer ring (physical \& sexual violence) are explicit, forceful and often intense in nature that reinforce the regular use of other subtle methods of abuse. The types of DV stated in the inner and the outer circle of the wheel are universal in nature and applicable globally (Pence \& Paymar, 1993). The study findings actually reinforce the cross-cultural validity of the wheel. 


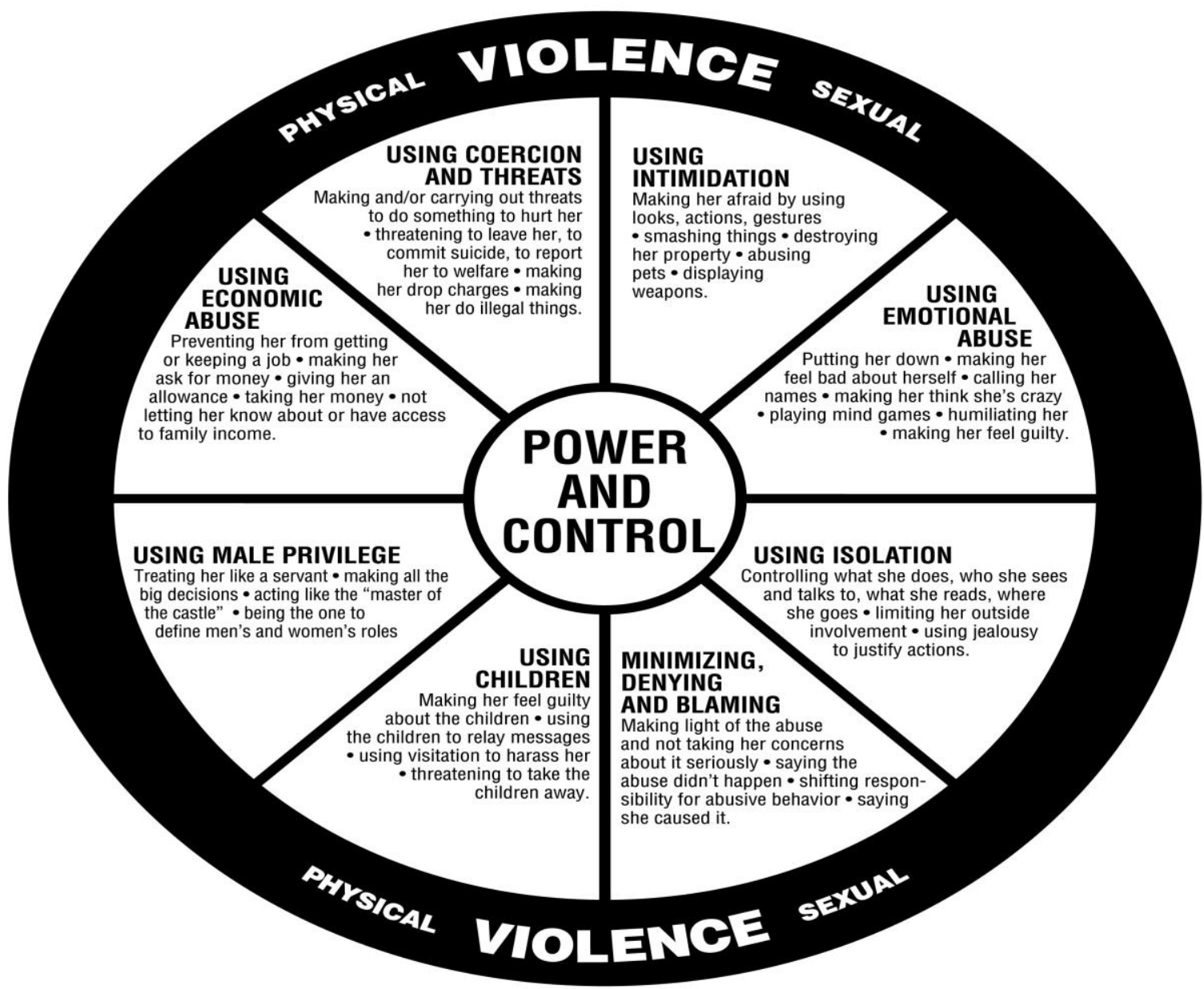

Figure 1. Duluth Power and Control Wheel

\section{Method}

The participants for the current study $(N=21)$ were recruited from four community-based organizations that work with survivors of DV in Mumbai, India. One organization was a crisis center located in a peripheral hospital; the other three were community-based women's organizations. To be included in the study, a woman had to have been abused by an intimate partner and then sought help in one of the four agencies serving DV victims. Upon approval from the Institutional Review Board at Wright State University, the staff at each of the four agencies was contacted and asked to review the case files of survivors whom they deemed emotionally able to participate in this research study. After the initial assessment, the staffs of the agencies sought the permission of the women they identified, requesting that they meet the principal investigator (PI) at the corresponding agency. The PI visited each agency and described the study in greater detail to each woman, in a private individual meeting, where the PI read the consent form to her aloud in either Hindi, Marathi, or English, based on the participant's preference. After hearing the explanation of potential risks and the voluntary nature of the study, women who decided to participate signed the informed consent form and completed a one-time, in-depth interview. In cases of women with children, care was taken to leave the children out of the room and out of earshot so the children were not exposed 
to hearing any history of violence. Interviews lasted from 1 to $3 \mathrm{hr}$. The interviews were audiotaped with the participants' consent and then translated into English and transcribed.

\section{Data Analysis}

The coauthors applied an open-coding strategy defined by Saldana (2016) to identify the lived experiences of Indian women experiencing DV. In practice, this meant that the study's two coauthors divided the interviews, with one of them coding 10 interviews and the other coding 11 interviews. During the initial step of the data analysis process, the authors independently read, interpreted, and coded the data. Then, they independently categorized the codes according to themes. Finally, they jointly discussed the meanings elucidated in the data (Ulin, Robinson, \& Tolley, 2005). As the data were coded, jointly discussed themes were compared with independently developed themes and hence emergent coding was utilized as new connections and typologies were uncovered. The final codes were labeled to reflect the full data set (Glaser \& Strauss, 1967). The final set of 16 codes was derived using an iterative individual open-coding process followed by consensus.

The 16 codes were as follows:

1. Abuse during pregnancy

2. Constant back-and-forth between natal and in-laws' families/dropped off or sent to mother's without returning home

3. In-laws' involvement in abuse (in-laws' perceptions that household duties were being performed inadequately)

4. Different types of abuse-physical, emotional, verbal, sexual, financial, neglect, taunts about looks, insensitivity toward emotional needs, demands for money/gifts from natal home, husband's infidelity, husband listening to parents but not his wife, suspiciousness (of her), public embarrassment (of daughter-in-law), burning wife's and daughter's clothes, threatening to kill older son, accusations about spending

5. Neglect of children

6. Abuse of children (sexual, physical, and/or emotional)

7. Demand for divorce

8. Lack of financial maintenance by husband

9. Demand for/taking money from natal family

10. Financial condition in natal home (difficult to care and provide for kids)

11. Social and family pressure to stay in the marriage or woman's attempt to stay married

12. Social isolation

13. Forced into marriage

14. Self-protection and involvement of police and/or hospital

15. Cycle of violence

16. Advice from others

Next, magnitude coding (Saldana, 2016) was used to assess the frequency of the 16 codes and consolidate the codes under larger categories (see Table 1). Coded material was reorganized as needed so that it best fit the larger theme. For example, "husband listening to parents but not his wife" was moved under the theme "Family involvement in abuse" rather than staying under the larger theme "Different types of abuse." Also, Code 14 (Self-protection and involvement of police and/or hospital) and Code 16 (Advice from others) were not included in the final themes, as they did not appear as frequently as the other codes. 
Table 1. Final Categorization of Codes Into Themes

\begin{tabular}{|c|c|}
\hline Category & Coded Data \\
\hline \multirow[t]{6}{*}{ Types of abuse } & Abuse during pregnancy \\
\hline & $\begin{array}{l}\text { Different types of abuse-physical, emotional, verbal, sexual, financial, taunts } \\
\text { about looks, neglect, insensitivity toward emotional needs, demands for } \\
\text { money/gifts from natal home, husband's infidelity, suspiciousness (of her), } \\
\text { public embarrassment (of daughter-in-law), burning wife's and daughter's } \\
\text { clothes, putting salary in the hands of in-laws but still accused of spending } \\
\text { money unnecessarily (don't know what she does with the money) }\end{array}$ \\
\hline & Husband in second marriage—not giving her due maintenance \\
\hline & Demand for/taking money from natal family \\
\hline & Social isolation \\
\hline & Cycle of violence \\
\hline \multirow{5}{*}{$\begin{array}{l}\text { Family } \\
\text { involvement in } \\
\text { abuse }\end{array}$} & In-laws' involvement in abuse \\
\hline & Household duties-abuse due to not cooking properly \\
\hline & Husband listening to parents but not to wife \\
\hline & Forced into marriage \\
\hline & $\begin{array}{l}\text { Social and family pressure to stay in the marriage-woman's attempt to stay in } \\
\text { the marriage }\end{array}$ \\
\hline \multirow{3}{*}{$\begin{array}{l}\text { Treatment of } \\
\text { children }\end{array}$} & Neglect of children \\
\hline & Abuse of children—sexual, physical, and/or emotional \\
\hline & Financial condition in natal home-difficult to care and provide for kids \\
\hline Abandonment & $\begin{array}{l}\text { Constant back-and-forth between natal and in-laws' families/dropped off at (or } \\
\text { sent) to mother's place without returning home (in some cases resulted in } \\
\text { husband's demand for divorce) }\end{array}$ \\
\hline
\end{tabular}

\section{Results}

\section{Participants}

The mean age of the participants was 31 years. Participants' marital statues included married $(n=14)$, separated $(n=5)$, and widowed $(n=2)$. Fourteen participants (two thirds) reported not living with the abuser; the other seven were still living with the abuser at the time of the interview. The average age of the participants at the time of marriage was 18 years, with a range of 12 to 24 years old. On average, participants had been married for 12 years. The average number of years participants had endured abuse was 9 . The majority of participants were employed $(n=11)$; one third $(n=7)$ were unemployed, two were in training or school, and one was retired. Among those employed, jobs included housekeeping, clerical work, cooking, teaching, patient care, and sewing. The average annual income level of participants who worked was 50,000 rupees, whereas the average annual family income was 129,000 rupees. The average level of education among participants was twelfth grade (similar to high school level in the United States). Highest levels of educational achievement ranged from third grade to partial completion of a master's degree. The religious identifications of participants were Hindu $(n=13)$, Buddhist $(n=5)$, Muslim $(n=2)$, and Christian $(n=1)$.

In line with the power and control wheel (see Figure 1) applied to DV studies (Pence \& Paymar, 1993), women in the current study described the complex ways in which they were trapped in abusive relationships. The lived experiences described by the abused Indian women fit in four main 
categories, as reflected in Table 1: (a) types of abuse, (b) family involvement in abuse, (c) treatment of children, and (d) abandonment.

\section{Types of Abuse}

The 21 participants were exposed to many types and combinations of physical, psychological, sexual, and/or financial abuse. Forms of abuse included being hit with objects; being belittled for their looks, for not cooking properly, or for having little or no access to money; and forceful sex. Women also talked about their husbands having an affair, getting a second wife (legal or illegal), and demanding money from the natal family as other types of harassment and abuse. Most women also experienced abuse and neglect during pregnancy. For example, partners were physically abusive and insensitive during pregnancy and/or at the time of labor, did not give his wife enough rest at the time of pregnancy and/or post-partum, and absconded when the baby was born. One participant talked about how her partner's abuse at the time of pregnancy led to her miscarriage:

Abusing is there, and about beating, he has beaten me once or twice. Due to one of the physical fights, I miscarried once. He had beaten me so much that I cried a lot-in that pressure I miscarried. It was so dangerous that there was blood flowing from the cord. (Meghna) ${ }^{1}$

The following comment, made by one of the other participants, shows the insensitivity of the husband and his family after the birth of the baby, who died when only a few days old:

My baby was in the hospital for four days-even I was there for four days. Without informing me they came and took this elder daughter to [place name omitted]. I was in the hospital for four days with my younger daughter. Nobody asked about me and my daughter-not my husband, not my fatherin-law, mother-in-law; nobody asked about us [crying]. That baby expired on July 14 th. (Radha)

Abuse during pregnancy was not the only form of abuse the women experienced. Another participant shared that, when she questioned her husband's affair, she was beaten more severely. She shared,

I said [to my husband], "Why did you lie to me?" That girl [with whom husband had an affair] told me all. .. So from that day on, he thrashes me every day; he made living difficult for me.... He would start fighting right in the morning and fight 'til it was time to sleep at night. He stopped any physical relation with me. (Sita)

Demanding money and gifts from the natal family was another phenomenon commonly shared by participants. One participant shared,

Like we ask for money-once he asked for 25,000 rupees. . . He said, "Your daughter has kids and she has to go to farm for work, to avoid this, [to] take a mill for her.” For that, he took 15,000 rupees from my mother. (Radhika)

\footnotetext{
1 Throughout the article, pseudonyms have been used to protect participants' identities.
} 
Radhika's husband also married another woman without divorcing Radhika, even though it was illegal to do so. Radhika stated,

It's not legal, but the police say, "You bring a proof," means, a photo of [them] both garlanding each other. Now, I don't know in which temple or where this marriage has taken place. He openly lives with that girl. ... My husband has not given a single month [of] maintenance [support] so far. It's been three years, [and] he has not been bearing my expenses. (Radhika)

Social isolation was another way the women experienced victimization. For instance, Sita spoke of how others lived nearby and were aware of the abuse but ignored her situation: "He used to beat me a lot. No one used to come ever, even though there were so many people around." A few participants discussed a change in their partner's nature after getting married. One participant (Sita again) reported, "He was nice one month before marriage, but after two months of marriage, his real behavior unmasked. He used to drink a lot and beat me badly. They used to blame me for having affairs with others." Another participant, Reena, similarly stated, "After getting married, his nature changed. Within four days he changed-he only wanted hard-working women. His nature was like, 'Get money from home and don't trouble me for anything.' He was good with me only for four days." This participant went on to discuss the cycle of violence that occurred in her marriage:

I still used to think, "Let it go; I can't live with my parents after marriage." In the end, [my] in-laws' home is my home now. So, I used to cry but try to stay [in my marriage], but it was too much trouble for me. So, I would inform my parents of this, and my brother would take me back. I used to think that he would calm down and forget his anger in four days and would behave properly again. After going back, there was the same trouble after two days: always beating [me], not giving [enough] food to eat, and continuously doubting my character. (Reena)

\section{Family Involvement in Abuse}

The intimate partners were not the only ones involved in the abuse; in most cases, the in-laws also abused the women (their daughters-in-law). Women in the current study lived with their in-laws. Differences in daily routines and in cooking and cleaning styles were common causes of conflict between mothers-in-law and daughters-in-law. These differences led to several episodes of physical and verbal abuse.

In most cases, the husband was an accomplice in the conflict or a bystander who gave no support to his wife. If the conflict arose while the husband was at work, he would believe his family's version of the story instead of his wife's. The following comment by one participant shows how she was taunted for these lifestyle differences:

He lives in a village and we live in city area. Our lifestyle is different from theirs. I didn't know the lifestyle of villages. They stop me from doing anything and everything. They question me about even very petty things like, "Why do you walk like this?" "Why do you eat this?" [and] "Why do you drink this?" (Rama)

Another participant shared an example of a physically abusive mother-in-law. This participant's husband would abuse her on the basis of what the mother-in-law said. She reported, 
Yes, mother-in-law also beats me ... holding my hair, twisting my hand backwards, kicking and punching, hitting on the head ... on a simple thing, my mother-in-law would tell him something, and then he would beat me up. (Radhika).

Another participant shared an experience in which her father-in-law became physically abusive toward her:

I never answer back, but that day I became angry. My father-in-law left [from] bathing, came inside the room, and thrashed me so badly for such a trivial thing. He pulled my hair and thrashed [me] in public. My husband, mother-in-law, and sister-in-law were standing and watching, and my fatherin-law used very bad language on me. I never heard them [those words] before. (Sita)

Women were taunted for several reasons, including for not cooking properly. A participant shared,

When I used to cook food, my mother-in-law would say, "Something is pungent. Use less salt on that. She would call me names and assault me. And when [my] husband had gone out, [my] brother-in-law used to come running at me to beat me. [My] mother-in-law also used to beat me. (Anna)

Most participants also complained that their husband would not believe their version of what had occurred. Radhika shared, "He mostly listens to my mother-in-law. He doesn't use his brain. For everything, he listens to his mother. He would do as his mother told him. My husband is like that."

In addition to in-laws' roles in abuse, the natal families also contributed-in some cases, abusing the women even before they got married. One participant shared that she wanted to finish her education and not get married, but her parents forced her to marry:

I said, in my mind, I did not want this marriage, and my marriage also took place very early. I was studying in school. I did not even appear for a math paper [exam] in the school. They let me continue my education 'til seventh [grade] standard and then immediately married me.... What I said to Papa [was this]: "Papa, there is one month until my marriage. I don't want to get married. I don't like that boy. I don't want to get married. I want to complete my education." (Anna)

Participants experienced a lot of social pressure to reconcile with their abusive husband, return to the in-laws' home, and stay in the marriage. Participants felt this pressure from both their natal family as well as the abuser's family. One participant reported,

So, I thought, "Even if I go to my mother's place she would keep me for four days, [but] my brother and brother-in-law are also there. They'd also say that a woman earns respect only when she lives in her husband's house, not in her parent's house. .. . I have to go where my husband is. That is my true home." Why does this happen with women? I don't understand that. If [your] husband tortures you, where can you go? She can neither live with your husband nor go to your mother's place. What can a woman do? There are orphanages for women, but what will you do there? That is also of no help. I hear that all sorts of bad things happen there. . . . Sometimes I sit and think: 
"Where should I go? I can't live with my husband-he beats me-but if I go to my mother, my brother and his wife would object. So where can I go?" (Nazia)

Sometimes the pressure to reconcile with the abusive husband was for the sake of their children. In several cases, women caved to this pressure. For example, the following participant shared how she was told that her husband could provide a house and fatherly love, which she was incapable of providing for their son:

My parents ... said that a husband is a husband. "You're young now," [they said]. "What will you do alone? What else can you do in the future? Can you provide a house for your son, or paternal love? ... at least he [your husband] will get a house and a secure future." So, I accepted him. (Sita)

\section{Treatment of Children}

The participants described the various ways in which the abuse affected their children. These effects included abuse and/or neglect of the children or the children being used by their parents as pawns. In some cases, the children were allowed to leave with their mothers and go to a safe place (in most cases with the natal family), but in some situations, they were not allowed to do so. In such cases, the children were used as tools to harass and threaten the women. Women also complained about their abusive husbands being sexually abusive toward other girls in the extended family. Such abuse prompted these women to move out of the home for fear of what the abusive husband might do to their own daughters. The following comment by one of the participants highlights this concern:

He was trying to misbehave with his sister's daughter and then again with his brother's daughter. ... He would try to be sexual with any and all women.

... When I saw that he was trying to do the same thing with his own daughter from [his] first wife, I raised my voice. He hit me very badly. How much can I tolerate? . . . It'd be better if I take my daughter away from such a wolf, [to] work and [be able to] feed her. (Razia)

The following example reveals one daughter's suicidal thoughts related to physical abuse she endured at the hands of her father. The mother described one situation:

Once I came back. . . . There was a big box of steel, which he threw on her [the daughter's] leg. It hurt my daughter and blood came out. She cried a lot. Later she told me that she would kill herself. I said to her, "I gave birth to you. I raised you with so much difficulty. How could you say you will kill yourself? I did not bear you so you could kill yourself." She said, "No, father beats me, and no one is there to stop him or say something to him. So, it's better to die than to bear all this." (Bindu)

There were several cases of sheer lack of responsibility by the husband. For example, one husband would not provide for his family financially, refusing to pay either for household expenses or for food:

Rice or wheat is so expensive; pulses [food] are so expensive; then there are other expenses also. Children want to eat something. They are kids. They see something and want to have it. So how would I meet the expenses when he doesn't work? Only when you work can you meet the expenses [and] run your household. When you don't work, there is always going to be a shortage. (Nazia) 
In some cases, the abusive husband did not even bother to buy simple things, like a snack for his son, instead placing the entire responsibility for the children on his wife. One participant, Radhika, reported, "He does not buy a single thing for me. When he comes here in the court on a date, he doesn't even give a box of biscuits [cookies] to my son. I have to take care of everything." It was not just a lack of financial responsibility for the children. In some cases, the children were used as a means to threaten the woman. The following comment illustrates this type of threat:

He would pressurize me, [saying], "If you say [that] I have beaten you up or [that] I have branded you-if you said something, then afterward, we [husband and in-laws] would kill your son." They would threaten like that. That's why they have kept my older son with them so that I don't say anything anywhere. They threaten me by holding my older son for ransom. "We would kill him. We would give him poison." He is a small kid [and] it's a village over there. People throw medicine bottles anywhere. They would make him drink it and say, "He must have picked [up] a bottle from somewhere and put it to [his] mouth." They threaten me like this, and so I want to bring my older son over here [in-law's home]. (Radhika)

Because of threats like these, the protection and safety of children played a key role in women's decisions about whether to say in (or return to) their abusive marriages.

\section{Back and Forth and Abandonment}

Most women in the current study described how they had to constantly move back and forth between their natal home and their in-laws' home, sometimes for months or even years. In certain cases, the DV in the marital home was so severe that the woman had to look for an opportunity when nobody was watching to call her natal family to come rescue her. The process of negotiation would involve the woman receiving social pressure from the husband and husband's family to do as they desired. In most cases, the woman's parents, brother(s), and/or extended family got involved. In several other cases, the woman was cajoled and dropped off at the natal home with the promise that she would be picked up in a few days to return to the marital home. In some cases, but not all, the children were dropped off with her. In these cases, the promise was not kept—the women were never allowed back into the marital home. The husband would abscond or in some cases even serve her a divorce notice so that he could legally get a new wife.

One of the participants (Rama) shared an experience in which it was implied that she was not intelligent enough to be a daughter-in-law in her husband's family. She explained, "He says we don't want a daughter-in-law like you; [he says] we want an intelligent bride who can take care of the family and the house, even though I used to do everything for them." Another participant shared how her husband promised she could live separately from her in-laws, but instead was dumped at her parents' home, only to find that they did not want her anymore.

So now I have had enough. He brought me here [to my own family] on the pretext of staying apart from his parents. He told me, "My parents torture you, so come with me. We will stay away from them separately." How would I know that he'd leave me in my parents' house? ... [H]e convinced me that we're going to live separately, but he fooled me and left me. He didn't stay at my house lest my parents should talk to him. Now what to do? (Naina) 
Women went back and forth for several weeks, months, or even years between their natal home and their in-laws' home. The following example sheds light on this phenomenon:

Yes, it's going on [and on] like this. ... I would have lived there [at the marital home] only for eleven months since I got married. The rest of the days I have lived here [at my natal home] only. They [in-laws] would take me there only for their work. When their work is done, they [in-laws] would assault me again and send me back. After only four months they [in-laws] would send me. After only two months they [in-laws] would send me here [natal home]. (Anna)

Another participant, who was sent to her natal home, and had been living there for the past 6 months, shared how her husband was demanding divorce.

Now he says that he wants to divorce me. "I am not sure," his family members are saying. They don't let me talk to him. I also want to ask him for sure whether he actually wants divorce. His family says: "He is not your husband. You are not allowed to talk to him.” (Naina)

In this manner, women constantly bounced between their natal and marital (or in-laws') homes, often finding themselves at the hub of conflict among and between the families. On several occasions, the abused women were subject to the whims of her husband and/or in-laws, and did not have a real voice in the decision-making.

\section{Discussion}

This study had several limitations. The small convenience sample of participants was drawn from community-based organizations in the city of Mumbai. Thus, generalizing the results to other populations without similar contextual factors (e.g., urban, low-income backgrounds) is limited. The interviews were conducted in two different regional languages and later transcribed and translated into English. There is a possibility that specific meanings of terms or phrases may have been lost in translation.

Nevertheless, this study is an important contribution to the scant literature on low-income women experiencing DV in urban India. Families arrange most marriages in the Indian society. Thus, a marriage is not simply between two individuals but between two families. For couples marrying, social status and/or class (caste in the case of Hindus, denomination in the case of other religions) is much more important than the ideal of two individuals falling in love. In the Hindu religion, when a woman gets married, it is common for the bride's family to provide dowry to the groom's family. This practice continues throughout the couple's married life, especially at the time of major holidays (festivals). Also, after marriage, women are considered a part of the in-laws' household and are at the bottom of the familial ladder. Abuse may be perpetrated not only by husbands, but also by both male and female in-laws (Adam, 2001; Anitha, 2011; Gill, 2004; Guruge \& Humphreys, 2009; Guruge, Khanlou, \& Gastaldo, 2010; Mason et al., 2008; Mehrotra, 1999; Raj, Livramento, Santana, Gupta, \& Silverman, 2006). The findings in our study demonstrate several situations in which family members were involved in DV. Abuse by the mother-in-law in particular was in line with research reported in other studies (Rew, Gangoli, \& Gill, 2013) and may be attributed, in part, to a female hierarchy centered on generation, and to the fact that she is the mother of a son. Women in this environment do not bond with one another, rather, a pecking order may become established, with the mother-inlaw assuming the highest position of influence and entitlement among the women in the family, and 
the daughter-in-law with the least (Raj et al., 2006). Moreover, abuse perpetrated by in-laws is in line with the Indian culture's patriarchal beliefs and traditional ideologies involving female inferiority. In most cases, women (both in India and other parts of the world) gain status by giving birth to a male child.

Due to the cultural norm that the husband is the only source of security, divorce or separation is not considered a feasible option for women, who are thus pressured to reconcile with an abusive husband (Goel, 2005). In addition to the stigmatization of divorce in the culture, children play a huge role in women's marital and life decisions. In the current study, children were the driving force behind women's decisions to either stay in or leave the abusive home. The urge to protect their children was some women's impetus for either separating from or reconciling with the abusive husband. Leaving or staying in the abusive relationship for the sake of protecting the children is in line with other research on abused women conducted in the United States (Bhandari, Bullock, Anderson, Danis, \& Sharps, 2011).

A unique finding of this study was abandonment by husbands. Although there is some documentation of abandonment in transnational marriages in India (Bajpai, 2013), the current study indicates that domestic marriage abandonment is also a huge problem. Women were sent to their natal homes on some pretext, and then the husband either absconded from the marriage or served the woman with a divorce notice. For women, the stigmatization of accessing the legal system, the long tedious process of court orders, and an utter lack of financial means, left abused women in helpless situations. Culturally, abandonment or serving a divorce notice defames the woman and her family. In Indian culture, a woman's identity is derived primarily from marriage and motherhood; therefore, a woman without a husband is treated as an incomplete person. Furthermore, a divorced woman and/or single mother is perceived as having failed in the role of wife and mother, regardless of the conduct of her partner (Dasgupta \& Warrier, 1996). This cultural perception leads to multiple disadvantages for women in India. On the one hand, abandonment by her husband, separation, and/or divorce are generally seen as evidence that the woman did something wrong or is flawed in some way. On the other hand, this perception leads to the woman's disadvantage in her natal home. Because the natal home is now the home of her brother's wife and their children, she may receive direct or indirect messages that she is unwanted there, too. Moreover, a divorced woman is shunned when she participates in holy events or celebrations (particularly weddings) for fear that she may bring bad luck (Ayyub, 2000). These cultural pressures, coming from all sides, leave abused women with very little choice in their lives, and thus, their best recourse is usually to force themselves to try to reconcile with abusive husbands.

\section{Implications for Social Work}

Taken together, the findings provide a direction for social workers working with abused women in community organizations in India. A multipronged approach needs to be adopted so women are not stigmatized, ashamed, or blamed for disclosing abuse. Social workers need to educate, train and sensitize the systems both at a formal level like health care, police, and courts and at an informal level like friends and families to respond to violence among women. Community organizations like Center for Enquiry Into Health and Allied Themes are already conducting state- and national-level trainings with health care providers, community abused volunteers, government officials and nongovernmental organizations on how to respond to DV. Such trainings need to be replicated at a much larger scale. Social workers need to be involved in raising awareness about DV in the community so that community members, including friends and family, facilitate the victims accessing services rather than stigmatizing them. Social workers should also undertake policy level advocacy for women who are abandoned by their husbands to help obtain victim compensation for 
damages. Victims in most cases are left to fend for themselves and their children. Finally, changing attitudes and levels of stigma towards women needs to be inculcated in all children from a young age.

\section{Conclusion}

DV in the Indian context is unique, as it is perpetrated not only by the intimate partners, but also by the in-laws. Abandonment by the husband is a real problem, and separation or divorce is heavily stigmatized in the society. A woman experiencing DV tends to seek help from her natal family or from community organizations to bring pressure on her husband to stop abusing her and her children. If these sources of help do not seem effective, the women may seek legal recourse as a last resort. In general, women are expected to endure violence for long periods of their lives for fear of bringing shame on their families and/or because of a lack of social and financial support independent of her husband. Future research could identify culturally acceptable ways to bring independence and financial strength to victims of DV.

\section{References}

Abraham, M. (1998). Speaking the unspeakable: Marital violence against South Asian immigrant women in the United States. Indian Journal of Gender Studies, 5, 215-241. doi:10.1177/097152159800500204

Adam, N. M. (2001). Domestic violence against women within immigrant Indian and Pakistani communities in the United States. Dissertation Abstracts International: Section A: Humanities \& Social Sciences, 61, 45-47.

Anitha, S. (2011). Legislating gender inequalities: The nature and patterns of domestic violence experienced by South Asian women with insecure immigration status in the United Kingdom. Violence Against Women, 17, 1260-1285. doi:10.1177/1077801211424571

Ayyub, R. (2000). Domestic violence in the South Asian Muslim immigrant population in the United States. Journal of Social Distress and the Homeless, 9, 237-248. doi:10.1023/A:1009412119016

Bajpai, A. (2013). Across the high seas: Abuse, desertion, and violence in transnational marriage in India. Violence against Women, 9, 1246-1262. doi:10.1177/1077801213506283

Begum, S., Donta, B., Nair, S., \& Prakasam, C. P. (2015). Socio-demographic factors associated with domestic violence in urban slums, Mumbai, Maharahstra, India. Indian Journal of Medical Research, 141, 783-788. doi:10.4103/0971-5916.160701

Bhandari, S., Bullock, L., Anderson, K., Danis, F., \& Sharps, P. (2011). Pregnancy and intimate partner violence: How do rural, low-income women cope? Health Care for Women International, 32, 833-854.

Charlette, S. L., Nongkynrih, B., \& Gupta, S. K. (2012). Domestic violence in India: Need for public health action. Indian Journal of Public Health, 56, 140-145.

Dasgupta, S. D., \& Warrier, S. (1996). In the footsteps of “Arundhati”: Asian Indian women's experience of violence in the United States. Violence Against Women, 2, 238-259.

Dreze, J., \& Khera, R. (2000). Crime, gender, and society in India: Insights from homicide data. Population and Development Review, 26, 335-352. 
Dutta, N., Rishi, M., Roy, S., \& Umashankar, V. (2016). Risk factors for domestic violence: An empirical analysis for Indian states. The Journal of Developing Areas, 50, 242-259.

Garcia-Moreno, C., Jansen, H. A. F. M., Ellsberg, M., Heise, L., \& Watts, C. (2005). WHO multicountry study on women's health and domestic violence against women. Retrieved from http://www.who.int/gender/violence/who_multicountry_study/en

Gill, A. (2004). Voicing the silent fear: South Asian women's experiences of domestic violence. The Howard Journal of Criminal Justice, 43, 465-483. doi:10.1111/j.1468-2311.2004.00343

Glaser, B., \& Strauss, A. (1967). Discovery of grounded theory. Hawthorne, NY: Aldine.

Goel, R. (2005). Sita's trousseau: Restorative justice, domestic violence, and South Asian culture. Violence Against Women, 11, 639-665. doi:10.1177/1077801205274522

Guruge, S., \& Humphreys, J. (2009). Barriers affecting access to and use of formal social supports among abused immigrant women. Canadian Journal of Nursing Research, 41, 64-84.

Guruge, S., Khanlou, N., \& Gastaldo, D. (2010). Intimate male partner violence in the migration process: Intersections of gender, race and class. Journal of Advanced Nursing, 66, 103-113. doi:10.1111/j.1365-2009.05184.x

Kalokhe, A., Potdar, R., Stephenson, R., Dunkle, K., Paranjap, A., del Rio, C., \& Sahay, S. (2015). How well does the World Health Organization definition of domestic violence work for India? Plos One, 10, e0120909. doi:10.1371/journal.pone.0120909

Kamat, U., Ferreira, A. M., Motghare, D. D., Kamat, N., \& Pinto, N. R. (2010). A cross-sectional study of physical spousal violence against women in Goa. Healthline, 1, 34-40.

Koenig, M. A., Stephenson, R., Ahmed, S., Jejeebhoy, S. J., \& Campbell, J. C. (2006). Individual and contextual determinants of domestic violence in North India. American Journal of Public Health, 96, 132-138. doi:10.2105/AJPH.2004.050872

Mahapatro, M., Gupta, R. N., \& Gupta, V. (2012). The risk factor of domestic violence in India. Indian Journal of Community Medicine, 37, 153-157. doi:10.4103/0970-0218.99912

Martin, S. L., Moracco, K. E., Garro, J., Tsui, A. O., Kupper, L. L., Chase, J. L., \& Campbell, J. C. (2002). Domestic violence across generations: Findings from northern India. International Journal of Epidemiology, 31, 560-572.

Mason, R., Hyman, I., Berman, H., Guruge, S., Kanagaratnam, P., \& Manuel, L. (2008). "Violence is an international language": Tamil women's perceptions of intimate partner violence. Violence Against Women, 14, 1397-1412. doi:10.1177/1077801208325096

Mehrotra, M. (1999). The social construction of wife abuse: Experiences of Asian Indian women in the United States. Violence Against Women, 5, 619-640. doi:10.1177/10778019922181400

Panchanadeswaran, S., \& Koverola, C. (2005). The voices of battered women in India. Violence Against Women, 11, 736-758.

Pence, E., \& Paymar, M. (1993). Education groups for men who batter: The Duluth model. New York, NY: Springer.

Protection of Women From Domestic Violence Act. (2005). Retrieved from http://ncw.nic.in/acts/TheProtectionofWomenfromDomesticViolenceAct2005.pdf

Raj, A., Livramento, K. N., Santana, M. C., Gupta, J., \& Silverman, J. G. (2006). Victims of intimate partner violence more likely to report abuse from in-laws. Violence Against Women, 12, 936949. doi:10.1177/1077801206292935 
Raj, A., Sabarwal, S., Decker, M. R., Nair, S., Jethva, M., Krishnan, S., . . Silverman, J. G. (2010). Abuse from in-laws during pregnancy and post-partum: Qualitative and quantitative findings from low-income mothers of infants in Mumbai, India. Maternal and Child Health Journal, 15, 700-712. doi:10.1007/s10995-010-0651-2

Rew, M., Gangoli, G., \& Gill, A. K. (2013). Violence between female in-laws in India. Journal of International Women's Studies, 14, 147-160.

Sabri, B., Renner, L., Stockman, J., Mittal, M., \& Decker, M. (2014). Risk factors for severe intimate partner violence and violence-related injuries among women in India. Women \& Health, 54, 281-300. doi:10.1080/03630242.2014.896445

Saldana, J. (2016). The coding manual for qualitative researchers. Los Angeles, CA: Sage.

Sharma, I., Pandit, B., Pathak, A., \& Sharma, R. (2013). Hinduism, marriage and mental illness. Indian Journal of Psychiatry, 55, S243-S249. doi:10.4103/0019-5545.105544

Sinha, A., Mallik, S., Sanyal, D., Dasgupta, S., Pal, D., \& Mukherjee, A. (2012). Domestic violence among ever married women of reproductive age group in a slum area of Kolkata. Indian Journal of Public Health, 56, 31-36.

Sujatha, D. (2014). Redefining domestic violence: Experiences of Dalit women. Economic and Political Weekly, 49, 19-22.

Ulin, P., Robinsen, E., \& Tolley, E. (2005). Qualitative methods in public health: A field guide for applied research. San Francisco, CA: Jossey Bass.

Vindhya, U. (2000). "Dowry deaths" in Andhra Pradesh, India: Response of the criminal justice system. Violence Against Woman, 6, 1085-1108.

Visaria, L. (1999). Violence against women in India: Evidences from rural Gujarat, summary report. In B. Buton, N. Durvvury, A. Ranjan, \& N. Varia (Eds.), Domestic violence in India: A summary report of three studies (pp. 9-17). Washington, DC: International Center for Research on Women.

World Health Organization. (2016, November). Violence against women: Intimate partner and sexual violence against women [Fact sheet]. Retrieved from http://www.who.int/mediacentre/factsheets/fs239/en/

The Journal of Social Work in the Global Community, sponsored by Walden University, is a scholarly peer-reviewed journal that promotes research in the practice of international social work with a focus on social change. JSWGC publishes high-level research, literature and book reviews, and thought pieces related to the field of social work practice and social change in our global community.

Walden University Publishing: http://www.publishing.waldenu.edu 